\title{
Being Chhota Bheem in School: Implications for Education
}

\author{
Sonia Ghalian \\ Manipal Center for Philosophy and Humanities, India
}

\begin{abstract}
The thesis of this paper explores two notions of childhood, one that pervades school pedagogy and curriculum, and the other which we encounter in the larger popular media. In the contemporary context, a certain notion of childhood is central to school education. In other words, pedagogical practices and curriculum in school education carry within them a pervasive notion of childhood. This perception of childhood gets transmitted and manifested both at the classroom level and other tacit contexts through ideas such as discipline, hierarchy, punishments, and moral values among others. A notion of childhood is also communicated to children through family relationships and practices. However, a dominant and conscious sense of childhood is communicated to children through popular media like literature, television and films. The representation of childhood in these mediums also carries within it a sense of gender and moral values. This paper discusses implications of this phenomenon of learning in the context of curriculum reforms in school education.
\end{abstract}

Keywords: Construction of Childhood, School Pedagogy, Visual Media, Children's Film

\section{Notion of Childhood in School Pedagogy and Curriculum}

While defining the nature of power in modern societies, Foucault (1979) highlights how the establishment of modern day institutes such as mental asylum and prisons play a central role in shaping experience and defining identities in line with dominant discourses. The school as one among those fundamental modern institutes can also be looked at in this light, as that which operates within an implicit power dynamics. According to Foucault, the features of discipline are of primary importance in the establishment of schooling as a part of 'moral orthopedics' of society at large (Foucault 1980). In his analysis, Foucault illustrates the manner in which mandatory schooling is instrumental in controlling children both at a physical level and mental level. Thus, in lieu of Foucault's analysis of the implicit power dynamics in schools, the convention of defining what it is to be a child is of particular relevance within the field of education which moderates relationships between teachers and students.

The school as an institution is both formed on, and as well as indicates, structures of significance, legitimacy and domination (Giddens 1984), which provides children with a way of looking at themselves and the world. Popularly established the fundamental site of learning, the school provides a sequence of learning and experience to children that shape their world-views. In other words, it teaches children literacy as well as life skills. A child at school is taught how to read and write and attain knowledge of subjects like mathematics, science, history, geography, and English among others through the designed curriculum and pedagogy. The curriculum in a broader 
sense comprises manifold activities within the classroom such as reading and writing, as well as tacit learning manifesting outside the classroom room beyond the margins in spaces like playgrounds, assemblies and so on. Overall, the school links the quest for knowledge and development through a mode of instruction provided by teachers to students (Devine 2000, Gudmundsdottir 1996).

This discourse of pedagogy, that teaches children these knowledge skills, also carries within it, a certain notion about childhood itself. There is a very explicit division of child and adult in the architectural space of the school, which is further compartmentalized according to age, gender and ability. There is a strict concept of surveillance present in the school environment that is implemented through a structured timetable, examinations, timings and so on. Along with this formal structure, the space of the school carries a specific notion of childhood itself that then gets facilitated through various rules and their regulation. This formal structure of school pedagogy allows the pervasive notions of childhood to become part of the child's understanding of the world. Thus one can see that there is a certain sense of childhood that is projected onto schools that seem to mold the child for the better or in terms of what is thought to be desirable. Studies done by scholars (Pollard 1985, Darmanin 1995) indicate similar notions that are present in teachers' relationship with children, based on the discourses of productivity and positive social behavior.

A notion of childhood is implicitly and explicitly transmitted through various ways such as rules, discipline, gender, hierarchy, respect to elders, and seriousness and so on. For example, children at school are asked to put finger on their lips to maintain silence. This gesture of keeping silence carries an implicit understanding of discipline. Breaking the rule of maintaining silence leads to punishment. Thus, this idea of punishment in school itself carries a notion about how children and childhood is perceived and molded. A mischievous child is often seen as someone who is different from the rest of the class and needs to be disciplined. Thus the concept of discipline carries within it a concept of punishment (Foucault 1980). A child is made to stand outside class if he/she is found misbehaving in class. Here the space outside the classroom becomes a marker of punishment that teaches the child what is the right thing to do and what is not.

Some schools also have a detention hour that signifies spending time alone as a form of punishment for breaking the rule. Here isolation from one's peers has an implicit message that tells a child to not to act differently from the rest if one does not want to be alone. Nonconforming to the rules and methods of the school leads to punishment and isolation. Another manner in which children who break the rules are punished is by being told to stand on the bench. This image of a child standing with his hands up on inanimate object like a bench, to some extent reduces the child to that inanimate thing itself. This again implies that if a child does not behave according the rules, he will be nothing more than a bench.

In a large number of schools children are told to make separate lines for girls and boys while assembling for any form of activity. This bifurcation of girls and boys creates gendered spaces through which children learn of notions such as gender and sexuality. Children are also taught to be moral beings who do not hurt others, respect their elders and to not indulge in habits like stealing, bullying and so on. Language in which children are spoken to is based on moral values such as love thy neighbor, sharing is caring, speak the truth, a friend in need is a friend in deed and many more. All these moral values are not only a part of the pedagogical lessons taught to children, but also are a part of daily discourse of interaction between children and teachers. The signs of showing respect for the teacher are to stand up and wish her when she enters the class, not to engage in conversation while the teacher is speaking etc. Through such gestures a child is taught to be respectful towards elders. The crucial point to note from all the above examples is that, these are the ways in which the notion of childhood and perception of a child is constructed in school education. 
Most of the attitude towards a child in school is based on the 'needs' discourse (Foucault 1980), aimed to develop certain attributes and values in a child. Indeed, age, class and gender mediate this construction of childhood and its acceptance and resistance. All the above examples indicate a notion of childhood that pervades the school space and its pedagogical practices. Thus, the values that children learn at school, suggest a particular kind of image of what it is to be a child, both implicitly and explicitly. This notion of childhood at school is based on value added component of education and how it contributes to the overall cognitive and psychological development of children.

While Rousseau (1969) believed education of children could improve and conserve 'natural goodness' of human beings, education of children spread through publishing of books especially made for children with an aim to teach the values and norms of the society. Some researchers have indicated that the children's cultural products like books, along with the other forms of print and electronic media (television, magazine images), play an important role in offering visual images to children, which provides them with cultural information about themselves, others and their relationship with society (Spitz 1999, Yeoman 1999). Hurley argues "self-image in children is shaped in some degree by exposure to images found in written texts, illustrations, and films" $(2005,221)$.

\section{Construction of Childhood in Popular Media}

Due to the proliferation of media, the amount of popular texts (in written and visual forms) directed towards children has increased exponentially over the years. Today, some of the biggest media conglomerates in the world, like Time Warner, Walt Disney, and Viacom, are geared towards producing content for children. Cinema for children is predominant with Disney productions that have traveled across the globe and has influenced children of across cultures.

The study of popular media has been an important area among scholars to analyze the cultural histories of childhood, in terms of defining identity roles for children. In other words, there is a dominant and conscious sense of childhood, which is communicated to children through literature and films. According to Lesley Caldwell (2002, 4), "if myth of childhood actively shapes our epoch and ways of thinking, then cinema is the visual dimension of that myth where our modern commitments to the idea of the child are inseparable from its representation in visual form."

Along with this explicit sense of childhood, there is also a sense of gender and politics that is learnt through these mediums. To trace the portrayal of children as physically attractive, Avery, refers to the nineteenth century literature where child "hero had curly hair, blue eyes, and pearly teeth" Avery $(1965,176)$. There are some of the examples of how gender notions among children get established through the representation of beauty. The popular nursery rhyme (chubby cheeks, dimple chin) carries the notion of physical attractiveness of a child who becomes teacher's favorite due to her/his beauty. Stuart Hanson (2000) explores the notion of 'representation' of children in films. In his words he wants to think about "the notion of representation, since the cinema, like all media forms, does not re-present 'reality' despite the connotations of the term 'representation', how childhood is constructed and represented through cinema" $(2000,146)$.

In India, in order to discuss storytelling and construction of identities for children, Amar Chitra Katha, the comic book series holds an indisputable position. It is one of the India's prominent forms of popular culture for the English educated, urban children. Pai's $A C K$ series captured the imagination of Indian children and formed dominant ideas about Indian history and tradition. This 
0

is the manner in which notions of Brahmanism, masculinity and other modern day articulations of self-respect, merit, and hard work get propagated in the popular media of the 1970s (Sreenivas 2010, $6)$.

According to Michael Tomasello $(2000,12)$, children born in a particular cultural niche, learn in certain social contexts, which influence their knowledge of the world and benefit from the cumulative heritage of culture. The tales told and shared within these social interactions seem to construct a language for children, a language that forms the basis of their understanding, which is eventually internalized in the child. Understanding this, Zipes (2012) seems to insist that storytelling is one form of narrative that initiates children into knowing their social space and making meaning of the world. There are many scholars who argue that telling moral stories to children have been practiced for centuries to create a bond with children and to cultivate values and moral literacy among children (Narvaez 2002). In other words, telling stories can inculcate learning among children, which can change their attitude and behavior.

Another factor that has led to a change in the tradition of storytelling is the disintegration of joint family, particularly in the Indian context. Television and films to a large extent are now replacing the concept of telling stories by grandmother to children. By tracing the historical representation of children, we co-relate their representation in the contemporary times where print, television and films continue to provide content for children related to moral and gender roles.

In the Indian context one such popular character is Chhota Bheem. He has become part and parcel of every Indian household, where there is television series based on him as well as two popular animation films. Television cartoon programs like Chhota Bheem are not only sources of entertainment but also teach children values like punctuality, obedience, unity, friendship, kindness to people and animals, showing responsibility through visual storytelling and its child characters (Kannan 2014). These values and notions being represented also communicate to children of what it is to be a child, where they form an image of a child with certain qualities or attributes.

Chhota Bheem started to telecast in 2008 and it belongs to comedy and action genres. The program's song starts with a chirpy chorus "Bheem, Bheem, Bheem! Chhota Bheem! Chhota Beam," with a new episode every day, sometimes twice a day. Each episode runs approximately to 12 minutes to 14 minutes time duration. Earlier the program was available only in Hindi, English and Tamil. However, with the growing popularity, it is now available in other regional languages like Malayalam, Telugu, and Kannada.

Bheem borrows his name from the mythological character from the epic The Mababharata, where he is known for his strength and valor. The child version of Bheem is depicted to be a young nine-year-old mischievous and adventurous boy, who is the hero of the fictional village of Dholakpur. Just like Bheema of The Mahabharata, Chhota Bheem can lift enormous boulders, fight giants and save lives. He loves ladoos and often he is shown stealing them from Tuntun Aunty's shop. By eating ladoos, Bheem draws strength in order to fight the bully Kaalia and other bad characters who threaten the peace of his rustic village.

His gang, Chutki, Jaggu and Raaju, always carry a supply of sugary sweetmeats on their adventures. Chutki is a female character who has pink cheeks, crystal clear eyes, two ponytails and wears a traditional sari. She is shown to be very caring towards her friends and also helps her mother in the household chores. She does not forget to give Bheem his ladoos in case of emergencies. Surprisingly, she is seen greedy for desiring gold in one of the episodes. She has a soft spot for Bheem and often becomes angry whenever Bheem interacts with any other girl. Through these characters, gender roles and behavior get communicated to children. 
Kaalia is the antagonist in the story who is a plump 'pahalwaan' boy, and is shown to be always jealous of Bheem. He always tries to prove himself better, more powerful and smarter than Bheem but fails. The language used to describe his character is loaded with the negative attributes that a child or an adult should not have. He is a bully who plays pranks on people of Dholakpur, and he is greedy and jealous and often lands into trouble due to his foolishness. Sometimes, the characters call each other names like "stupid" and "fool/idiot," which is not the language taught to children at school. Moreover, words like stupid/idiot/fool are terms often used by school children to denote intelligence or the lack of it. Thus, the language used in both school and media have an impact on children and relates to a notion of childhood.

\section{Gap Between Two Notions of Childhood}

From the above observations, the two notions of childhood being constructed and represented in the school curriculum and the larger popular media for children seem to be sometimes contradictory to each other. Children at school seem to have less agency in terms of taking decisions on their own, as opposed to what is being portrayed through programs like Chota Bheem. Bheem and other child characters are shown to be in a state of power and control, who take important decisions about the entire village. In this aspect, we can say that they seem to take over elder roles with more authority and responsibility, unlike what occurs in a school space.

The manner is which discipline and obedience is taught in school is quiet different from its representation in Chhota Bheem. While a child is punished for breaking the rule in class, in Chhota Bheem the entire village rewards the children for fighting the 'evil' on their behalf. Though the intention to fight is shown to be a positive one, with respect to keeping the community of Dholakpur safe from the bad people, the representation of this heroism is depicted through fights, violence, schemes and chaos.

Though most of the values being depicted in programs and films like Chhota Bheem are more or less 'positive,' there are some contradictions in the portrayal of Bheem and other characters. Young children of age nine and ten are shown fighting with other villains and animals in the story, which may induce notions of violence and aggression among child audience. Emphasis on muscle power of Bheem is problematic as it goes against the notion of non-violence. Eating too many ladoos, as Bheem does can lead to health problem in children as ladoos and other sugary food items are high in cholesterol.

Gender roles portrayed through characters like Chutki creates a notion of beauty, as she is presented in a sari with pink flowers on it, brown hair, neatly pleated and the ever-glowing white skin and rosy cheeks. Chutki and Bheem share an intimate friendship and indulge in various adventures in various episodes. The childhood being presented as a world of adventure and indulgence is problematic when we see it within the schooling aspect of children. Since a child learns different notions about issues like gender, morals, discipline, honesty in school, what she sees in mediums like television and films, can affect their understanding of the world. As we have seen, Chhota Bheem is one of the most popular programs for children in India, as the children are interested to watch programs with child characters (Schmitt, Anderson \& Collins 1999), which influence them in many ways.

Thus we can see that children learn explicitly from television and films about images of childhood, gender and sexuality, and how these values are often at odds with what they are taught at school. There is a gap between media learning and school learning, where both play an integral role 
in shaping and influencing a child's world and constructing the very notion of childhood itself. Fox example, the influence of the media world impacts the learning of children in school especially when they deal with themes that are common to both the school curriculum and media for children.

Therefore, in order to bridge this gap between two forms of cultural influence, school and media on children, curriculum reforms in school should begin addressing the implications of this phenomenon. One way in which reforms in school pedagogical practices can begin is by incorporating media learning in curriculum and education of children. It is critical to recognize the influence of the medium itself and how children learn from it. Media being a form of storytelling provides a narrative for children that they can identify with. There have been studies done by scholars on how children learn effectively through the medium of storytelling. According to scholars (Taylor 2004 and Narvaez 2002) cognitive structure of children extracts themes out of the stories being told to them, as they identify themselves with the fictional characters and narratives to understand the expository text. They form their idea of what an adult should look like in films- men should be tall, then and somewhat hatchet-faced while women should be slim and attractive. The kind of tastes that children develop shows a deep internalization of gender roles and dominant notions that children form through their interaction in the society and what they see in the media.

\section{Possibilities in School Curriculum Reforms}

Given this state of our transnational, interconnected existence, where media dominates most of children's experiences in the contemporary society, school pedagogical practices cannot ignore the gap in the learning among children. Knowing this, how often do we use film in a classroom for education purpose? Though there is a rich relationship between children and popular media like films, it has not been analyzed from the point of view of incorporating film education as a part of school curriculum. Films are mostly seen as a form of entertainment (Field 1957) as opposed to its educative aspect among children. She gives the example of British film industry, where children tend to identify themselves with the child on screen, and do not like his/her ill- treatment, pain and suffering. Field also brings to fore the responsibility of adults in making children watch quality films. She puts forth the need for children to engage with the medium of film critically as films now have become part of our popular culture and a deep influencing potential both in terms of behavior and taste.

The media that children engage with provides them with imaginative spaces in which they create, play and perform stories. The narrative play is closely connected with children's identities and literacies shaping the stories they create. When we watch stories on TV, we play on the storyline- we have magical powers and we can save the world. At school, some children encounter a gap between their experiences of narrative at home and those that are valued in the literary classroom.

Becky Parry in her book Children, Film and Literacy (2013) demonstrates the educational quality of films to enhance literacy skills among children. She posits that through engaging with media, children develop understanding of the characteristics of narrative and the particular language of media. Children are able to express and develop distinct and complex understanding of narrative where they can draw on their own experiences. (They have a story in their head; they can think it through, but might be slow at writing). All too often they leave these experiences outside the classroom space. Most of the classroom spaces teach about having a story with a moral at the end. They have incredible stories to tell but lack the skills and knowledge to transfer these stories to media. Children need to have opportunities to tell stories in all media forms so their ideas and experiences are valued. 
She studies six UK primary school students using filmmaking practices to develop their literary skills. She showcases how to use media production in the classroom and explains how film classes at the primary level can contribute to advancing the understanding and interpretation of narratives for diverse learners with different literacy skills. She positions herself on the empowerment side of media literacy, criticizing research that addresses children as vulnerable and in need of protection from popular culture. She takes an empowerment approach on critically engaging with popular culture and promotes student's voices. She criticizes Giroux (2010) who "writes extensively about Disney as a global phenomenon rather than taking into account how children respond to any particular Disney texts" (Parry 2013, 11). However, before bringing filmmaking to the classroom, one needs to provide literacy of media and its affect on children so that they know how the media representation works and perpetuates dominant gender stereotypes.

Therefore, it becomes integral for school curriculum to expand its scope of learning and pedagogical practices that are inclusive in nature. One manner in which school curriculum can bridge the disjunction between what children learn at school and through media is by engaging with ideas which are being represented in media. The curriculum should be able to use the medium itself creatively to broaden the pedagogical practices at school. Films and television that influence children should be brought to the classroom space to explicitly study the nature of media and its modes of representation. Children's learning through popular media should be consciously included in conversations between children and teachers. Today, the curriculum is not limited to just the content about various subjects but also the medium through which the content is being taught. Films can be used to engage with children about various media representations and its relationship with society at large. They can be used to comment on films themselves. Showing films and documentaries on subjects like science and history can enhance the learning among children owing to its visual aspect. Film as visual media can be seen as potential medium for pedagogical practices and learning for children as it deals with themes children encounter in school and family space and also presents the world they inhabit in a new light. Having an understanding of the media culture through school curriculum can improve not only the quality of education but also make it more wholesome and rounded.

The English band, Pink Floyd's lead vocalist and bassist, Roger Waters, wrote 'Another Brick in the Wall' in 1979. It had three versions and the second one was on education. The song denied teachers thought-control over students. The song was a satire on the Victorian system of education, which secured homogeneity of populations, like products in an assembly line, through memory-based, rote learning, and thus leaving no scope for critique and inquiry. In that era of ships and handwritten data, education was all merely about transferring information from one part of the world to the other. But that was long time ago, when the world did not have television, films and new media. As we all know, this is not the case today. The effective use of media and its collaboration with curriculum practices can broaden the horizon for both children and education and also create newer and more complex notions of childhood and adulthood, which have important implications for teaching and learning. 


\section{Bibliography}

Avery, G. (1965). Nineteenth-Century Children: Heroes and Heroines in English Children's Stories 1780-1900. London, United Kingdom: Hodder \& Stoughton.

Devine, Dympna. (2002). Constructions of childhood in school: Power, policy and practice in Irish education. International Studies in Sociology of Education. 10, pp 23-41.

Darmanin, M. (1995). Classroom Practices and Class Pedagogies, in S. Delamont \& J. Salisbury (Eds) Qualitative Studies in Education. Avebury: Ashgate.

Field, Mary. (1956). Children's Taste in Films. Quarterly of Film, Radio, Television. 11, pp 14-23.

Foucault, Mitchel. (1979). Discipline and Punish: the birth of the prison. New York, United States: Random House.

Foucault, M. (1980). Power/ knowledge: Selected Interviews and other writings 1972-1979 by Mitchel Foucault. Hemel Hempstead: Harvester Wheatsheaf.

Giddens, A. (1984). The Constitution of Society- Outline of the Theory of Structuration. London. United Kingdom: University of CA.

Giroux, Henry. (1999). The Mouse that Roared: Disney and the End of Innocence. Lanham. United States: Rowman \& Littlefield Publishers Inc.

Gudmundsdottir, S. (1996). The Teller, the Tale and the One Being Told: The Narrative Nature of the Research Interview. Curriculum Inquiry. 26, pp 293-306.

Kannan, S. (2014). Depiction of Indian Cultural Values in the Popular Cartoon Program "Chhota Bheem" A Content Analysis. Global Journal For Research Analysis. 3. doi: 10.15373/47/22778160.

Lebeau, Vicky. (2008). Childhood and Cinema. London, United Kingdom: Reaktion Books.

Narvaez, D. (2002). Does Reading Moral Stories Build Character? Educational Psychology Review. 14, pp 155-171.

Parry, Becky. (2013). Children, Film and Literacy. London, United Kingdom: Palgrave Macmillan.

Pollard, A. 1985. The Social World of the Primary School. Biddles, United Kingdom: Guildford.

Rousseau, Jean Jacques. (1969). Emile, Julie And Other Writings. New York, United States: Barron's Educational Series.

Sreenivas, Deepa. (2010). Sculpting a Middle Class: History, Masculinity and the Amar Chitra Katha In India. London, United Kingdom: Routedge.

Schmitt, KL. Anderson, DR. Collins, PA. (1999). Form and content: looking at visual features of television. Developmental Psychology. 35, pp 1156-67.

Spitz, E. (1999). Inside picture books. New Haven, United States: Yale University Press.

Tomasello, Michael. (2000). The Cultural Origins of Human Cognition. Cambridge, United States: Harvard University Press.

Yeoman, E. (1999). 'How does it get into my imagination?' Elementary school children's intertextual knowledge and gendered storylines. Gender \& Education, 11, pp 427-440.

Zipes, Jack. (2012). The Irresistible Fairy Tale: The Cultural and Social History of a Genre. United Sates: Princeton University Press.

Sonia Ghalian is a PhD Scholar., Manipal Center for Philosophy and Humanities, India. 